\title{
ON THE STABILITY OF HOMOGENEOUS FUNCTIONAL EQUATIONS WITH DEGREE $t$ AND $n$-VARIABLES
}

\author{
GWANG HUI KIM
}

Abstract. In this paper, we obtain a generalization of Hyers-Ulam-Rassias stability for the family of the functional equation $f\left(\circ\left(x_{1}, x_{2} \cdots, x_{n}\right)\right)=H\left(f\left(x_{1}\right)^{\frac{1}{t}}, f\left(x_{2}\right)^{\frac{1}{t}}, \cdots, f\left(x_{n}\right)^{\frac{1}{t}}\right)$, where $H$ is a homogeneous function of degree $t$ and $\circ$ is an $n$-times-symmetric operation on the set $S$. As a consequence we can obtain the Hyers-Ulam stability.

Mathematics subject classification (2000): 39B52, 39B72, $39 \mathrm{~B} 82$.

Key words and phrases: Functional equation, homogeneous function, Hyers-Ulam stability, HyersUlam-Rassias stability.

\section{REFERENCES}

[1] P. GǍVRUTA, A generalization of the Hyers-Ulam-Rassias stability of approximately additive mappings, J. Math. Anal. Appl. 184 (1994), 431-436.

[2] R. GER, Superstability is not natural, Roczik Naukowo-Dydaktyczny WSP w Krakowie, Prace Mat. 159 (1993), 109-123.

[3] D. H. HYERS, On the stability of the linear functional equation, Proc. Nat. Acad. Sci. U.S.A. 27 (1941), 222-224.

[4] D. H. HyERS, G. ISAC AND TH. M. RASSIAS, Stability of the Functional Equations in Several Variables, Birkhäuser Verlag (1998).

[5] D. H. Hyers AND TH. M. Rassias, Approximate homomorphisms, Aequationes Math. 44 (1992), $125-153$.

[6] G. H. KIM, On the stability of functional equations with square-symmetric operations, Math. Ineq. Appl. 4, No 2 (2001), 257-266.

[7] ZsOLt PÁLES, Generalized stability of the Cauchy functional equation, Aequationes Math. 56 (1998), $222-232$

[8] Zsolt PÁLES, Peter VOLKMANn AND DUNCAN LUCE, Stability of Functional Equations with Square-Symmetric Operations, Proc. Natl. Acad. Sci. 95, Issue 22 (1998), 12772-12775.

[9] TH. M. RASSIAS, On the stability of the linear mapping in Banach spaces, Proc. Amer. Math. Soc. 72 (1978), 297-300.

[10] TH. M. Rassias, On the modified Hyers-Ulam sequence, J. Math. Anal. Appl. 158 (1991), 106-113.

[11] TH. M. RASSIAS AND P. ŠEMRL, On the behavior of mappings which do not satisfy Hyers-Ulam stability, Proc. Amer. Math. Soc. 114 (1992), 989-993.

[12] S. M. Ulam, "Problems in Modern Mathematics" Chap. VI, Science editions, Wiley, New York (1964). 